\title{
A Case for Surfacing Theories of Change for Purposeful Organisational Capacity Development
}

\author{
Alfredo Ortiz Aragón
}

\begin{abstract}
What are the capacities of an effective social change organisation (SCO)? Some SCOs may value strategic planning capacities, while others financial accountability to donors, improved teamwork, or networking capacities. But do the different capacities that SCOs seek purposefully support meaningful social change? How much of what SCOs deem as 'worth strengthening' is based on linear thinking, or unhealthy power interests, or what donors want them to want, or a combination of these? This article argues that the capacities that different organisations value are conditioned by a mix of individual, organisational and societal worldviews, including deeply held assumptions on the nature of change and one's roles in affecting change. It posits that the processes SCOs use to attempt to intentionally 'build' their capacities should surface these worldviews in order to find more purposeful and systemic relationships between its internal processes, systems and capacities and the complex change that an organisation seeks to support.
\end{abstract}

\author{
1 Introduction \\ This article takes the point of view that the \\ capacities that different organisations value are \\ inherently conditioned (but not determined) by a \\ mix of individual, organisational and societal \\ worldviews, including deeply held, often implicit \\ assumptions on the nature of change (i.e. \\ theories of change) and one's roles in affecting \\ change. One common worldview found in the \\ development industry is the belief in a simple \\ cause and effect logic between what a social \\ change organisation (SCO) does and actual \\ social change. This linear logic - although \\ perhaps convenient for 'simplifying the world' in \\ planning processes - sees the world from the \\ perspective of its own instruments (Bakewell and \\ Garbutt 2005; Earle 2002; Kaplan 1999; Reeler \\ 2007), and does not take into account the \\ inherent complexity of social change. In addition \\ to this worldview, there are others which \\ reproduce elements of culture and power that \\ affect an SCO's capacity to act upon the \\ boundaries that constrain and enable its social \\ action (Hayward 1998: 12), and which may be \\ contrary to the values and purposes that the \\ SCOs espouses. The article argues that the
}

processes SCOs use to attempt to intentionally 'build' their capacities, should surface worldviews and theories of change in order to find more purposeful and systemic relationships between the complex change that an organisation seeks to support, and its internal processes, systems and capacities. This non-linear 'purposefulness' can help SCOs develop the specific, contextual capacities that are needed for grappling with and making sense out of social change, and in the process develop a healthier relationship with their environment.

\section{Capacity and purposeful change ${ }^{1}$}

Capacity has been defined very broadly, e.g. '[C] apacity is understood as the ability of people, organisations and society as a whole to manage their affairs successfully' (OECD 2006: 12); and more narrowly, e.g. 'Capacity is the ability to carry out stated objectives' (LaFond and Brown 2003: 7, quoting Goodman 1998). It has been qualified with value judgments about its proper use, e.g. 'Capacity represents the potential for using resources effectively and maintaining gains in performance with gradually reduced levels of external support' (LaFond and Brown 2003: 7); 
and it has been defined with minimalist simplicity, e.g. 'Capacity is [the] potential to perform' (Horton, Alexaki, Bennett-Lartey et al. 2003: 18). It has been divided into 'hard' capacities such as 'infrastructure, technology, [and] finances (Horton et al. 2003: 23), and 'soft' capacities, such as the '...human and organisational capacities, or social capital of the organisation, including such things as management knowledge and skills, ... organisational systems and procedures, ... and procedures for planning and evaluation' (Horton et al. 2003: 163). The 'soft' capacities have been divided even further, between those which appear to be more 'tangible' and 'intangible'. The former refers to the systems and processes mentioned above. The latter refers to capacities which highlight the importance of an organisation having the 'ability to function as a resilient, strategic and autonomous entity' (Kaplan 1999: 20), as well as having the capabilities to commit and engage, adapt and self renew, relate and attract, and balance diversity and coherence (Baser and Morgan 2008; Morgan, P. 2006). ${ }^{2}$ Merriam-Webster's online dictionary defines one aspect of capacity from the perspective of power: 'the facility or power to produce, perform, or deploy'?

Capacity is meant to be put to use, to 'enable a human system to create value' (Baser and Morgan 2008: 3). The oft posed question 'capacity for what?' (Baser and Morgan 2008: 31; Lopes and Theisohn 2003: 25; OECD 2006: 19) is often met with the response: 'performance', ultimately in support of emergent, positive change. ${ }^{4}$ Morgan broadly elaborates the concept of capacities for performance:

Capacity has to do with collective ability, i.e. that combination of attributes that enables a system to perform, deliver value, establish relationships and to renew itself. Or put another way, the abilities that allow systems individuals, groups, organisations, groups of organisations - to be able to do something with some sort of intention and with some sort of effectiveness and at some sort of scale over time. (Morgan, P. 2006: 7)

So, capacity should help support performance towards purposeful social change - which makes capacity strengthening a potentially attractive endeavour, especially considering the abundance of critical observations on the development 'performance' of many social change organisations. ${ }^{5}$ But what is the nature of the relationship between capacities and social change? Does one cause or guarantee the other, or does development complexity render the concept of purposeful capacity development an unhelpful oxymoron?

\section{Balancing purposeful capacity development with the complex, non-linear nature of social change}

As a capacity building practitioner, I would like to believe that there is some constructive relationship between that which I and the SCOs 'do' and actual positive change. This could be thought of as a desire for there to be some sort of effective 'impact' emanating from our work. But whether a link actually exists is questionable in many cases because of the assumptions on which many organisational interventions rest. When examined closely, organisational assumptions can be found which reveal a linear worldview, i.e. the belief that between what the organisation does and the change it seeks to support there is, or should be, a direct cause and effect relationship. This underlying belief, and the linear intervention models that often accompany it, might make sense if human social change could be characterised by well-understandable and welldefinable, 'hard' problems, which lend themselves to 'engineerable' objectives and solutions. But social change is anything but straightforward; consider the following questions:

What should be done to address the predicaments of street children in Lima, Peru? What should be done to conserve areas of high biodiversity and poverty in Ecuador? How can education of girls in conservative regions of Afghanistan be approached?

These are not bridges or dams to be built. Each of these not uncommon problematic situations might have multiple stakeholders, none of whom exactly agree on the nature of the problem, or on what might constitute a meaningful response. Checkland (1993: 316) distinguishes 'human' systems with their ill-defined 'soft' problems, which cannot be defined in simple means-ends language, because defining the 'ends, goals, purposes [is in itself] problematic'. With soft problems, I, as a practitioner, am not even sure precisely what the problems are, and even if I 
thought I was, any given stakeholder might have a different interpretation of the same problem. Soft, ill-defined problems are typical in the complexity of 'messy' human development, and require interventions, processes and systems that match the uncertainty and complexity of social change, i.e. that do not attempt to force predetermined, simplistic, causal solutions on complex realities. Understanding complexity and the non-linear nature of how social change and capacities 'emerge' is a starting point in rethinking what types of interventions might make sense in the face of this complexity.

\subsection{Complexity and the non-linear nature of how development emerges}

'Development is not linear and predictable... [therefore, w] e can never know quite what will flow out of a development intervention. There will always be outcomes which had never been planned, detours from paths..., unexpected reactions and contradictory achievements... Our assumptions will always be inadequate, although of course they must be made, for they form the foundation of any intervention; but always with due caution.' (Kaplan 1999: 12)

Complexity theory sheds light on the futility of assuming the development interventions of any particular organisation have more control over their desired ends than they actually do. One of the basic premises of complexity theory for development is that the directions in which development is going are often 'random and unplanned' (Morgan 1997: 6) and have little to do with where pre-set goals and well-planned development interventions intend for it to go:

Complexity theory posits that it is not possible to predict with any confidence the relation between cause and effect. Change is emergent. History is largely unpredictable. Organised efforts to direct change confront the impossibility of our ever having a total understanding of all the sets of societal relationships that generate change and are in constant flux... Small 'butterfly' actions may have a major impact, and big ones may have very little impact. (Eyben, Kidder, Rowlands and Bronstein 2008: 203-4)

The complexity of social change has implications for development practice. There is now a body of work arguing for the need to 'learn how 'to do' development differently by understanding the full complexity and non-linear nature of social change processes...' (Guijt 2007: 20).

Conventional approaches to development, which are often project-focused, are based on linear, cause-effect models of change which do not adequately take into account emergence, flexibility, adaptability and innovation required to deal with complexity (Britton 2005; Reeler 2007). Complexity renders causality inherently unknowable, and therefore planning and control in complex situations has limited utility (Baser and Morgan 2008; Earl Carden and Smutylo 2001; Earle 2002; Ramalingam and Jones 2008). Flood states that in complex contexts, 'anyone who honestly believes that they have everything under control is seriously out of touch with what is going on... [and] is badly mistaken in their aspirations' (Flood 1999: 91).

\subsection{The non-linear nature of how capacities emerge}

Some capacity development literature carries a similar message of complexity, arguing that capacity development interventions are not linear but occur in a distinctly more 'messy fashion' (Lusthaus, Adrien and Perstinger 1999: 15). Capacity development is an inherently political and complex process that is unstable and changeable (Watson 2006: 2). Due to the complex nature of capacity development, Morgan (1997: 6) argues that we 'require different ways of managing and measuring' capacity development interventions.

Yet, in spite of the non-linear nature of how capacities emerge, many authors have noted a continued prevalence of linear tendencies in capacity development. Baser and Morgan (2008: 49) note that current thinking about capacity issues has improved, in that it 'gives more attention to context, i.e. relating any interventions, internal or external, to the history, structure and pattern of the context'. But they find it is important to 'emphasise the complexity and the paradoxes of many context-actor relationships that do not conform to a linear pattern of cause and effect'. And they note the 'system blindness' of people everywhere, 'who see only parts of these systems at work and then make judgments about the whole;... see the present, but not the evolution or history of events that got things to the present;... misunderstand the nature of the relationships 
that shape system behaviour;... Much of the more rational, linear, quasi-mechanical approaches to capacity development lose relevance because of these blind spots' (Baser and Morgan 2008: 17). In addition, Morgan (1997: 12), referring to the design of capacity development indicators, notes that the oversimplification caused by 'mechanical and linear notions [of capacity development] so attractive to engineers, auditors and economists produce[s] little insight into the human behavioural aspects to do with learning, attitudes and values or organisational change'.

Indeed, capacity strengthening processes have also been criticised for not doing enough to support the effectiveness of social change organisations (Hailey, James and Wrigley 2005; Edwards and Fowler 2002; Lopes and Theisohn 2003), and '[s]ome are not convinced that capacity building makes any positive difference at all' (James and Wrigley 2007: i).

\subsection{Checkland's 'warning' ${ }^{6}$ - balancing purposefulness with complexity}

'We have to be able to see 'enough' and understand 'enough' to make sense of our world such that we can act meaningfully and purposefully within it.' (Burns 2007: 22)

So, on the one hand, there is a need to accept that the complexities involved in human change are real and render linear thinking generally unhelpful. But on the other hand, while it is important not to think linearly and instrumentally about how capacity development supports social change, it is also important to contextualise capacity development and try to approach it in ways that are 'not simply acting by instinct or randomly thrashing about' (Checkland and Poulter 2006: xvi). By 'purposeful' capacity strengthening I refer to processes that are better linked to what an organisation is trying to do, yet which take complexity into account - avoiding cause and effect thinking. I believe that capacity development is emergent and systemic:

Capacity is an emergent property that evolves partly through the pushes and pulls of contextual factors including global economic trends, national governance, the legacy of regional history and many others. The capacity of an organisation derives much of its character from its interaction with the bigger systems within which it is embedded.

(Morgan, P. 2006: 18)

This clarification is important because I believe that purposeful capacity strengthening can help social change organisations better grapple with complexity - not to be able to master it, but to be able to act thoughtfully and purposefully within it. Land, Hauck and Baser (2009) take issue with the term 'purposeful', insinuating linearity into the concept, as they clarify that as an emergent condition, capacity development '... is not driven by purposeful intervention and therefore cannot be managed in a conventional sense. Nor can it can be marshalled and adopted as a technique. However, it can be understood and influenced' (Land et al. 2009: 2, italics added). They are clear about the need to act differently on the basis of what the concept of emergent capacity permits:

By changing the way we look at cause-andeffect relationships, emphasising possibilities and probabilities rather than predictable results, it also challenges many assumptions about the need for planning, detailed design and control. In the process, it questions the way external partners set about influencing local change processes. Specific capacity development outcomes cannot simply be engineered by the delivery of external inputs. Interventions need to be flexible and able to adapt to future, usually unforeseeable, system behaviour. (Land et al.: 3)

The purposefulness 'worry' conveyed by Land and colleagues is expressed from a different angle by Mowles, Stacey and Griffin (2008), who consider that even complexity theory is in danger of becoming an instrumental, quasi-linear puzzle-solving approach. They argue that 'rather than offering a profound challenge to the very nature of development management... insights from the complexity sciences are instrumentalised and presented as another means of improving taken for granted ways of managing' (Mowles et al.: 805). The danger is that complexity theory is just seen as another 'tool' that can be 'applied it to ensure better results and more creativity' (Mowles et al.: 810).

The core 'worry' expressed by both of these concerns I believe is best exemplified by Checkland's (2000: S18) representation of hard 


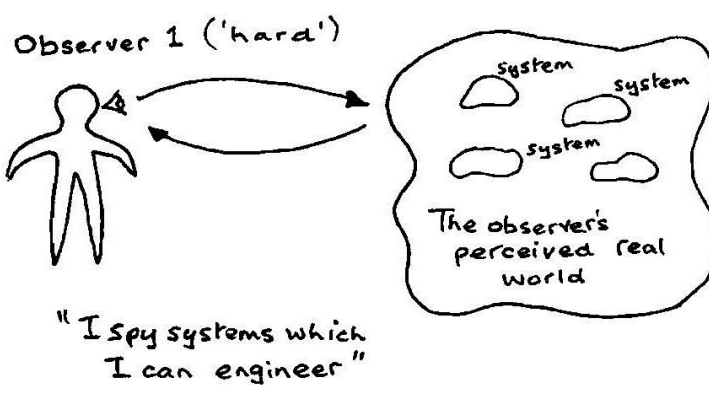

\section{The world: systemic}

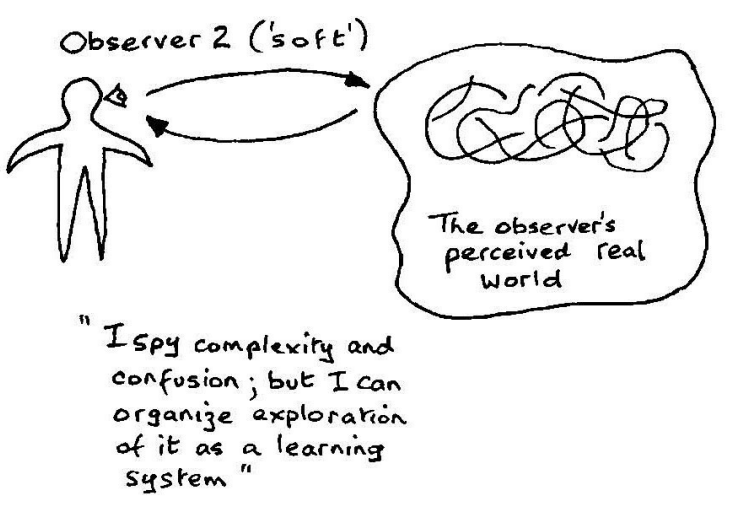

The process of inquiry:
systemic

and soft systems stances (see Figure 1), in which he offers two classic worldviews - that of the 'hard' systems observer who spies a systemic world with systems he can engineer, and that of the 'soft' systems observer, who spies complexity and confusion, and therefore resorts to systemic inquiry (i.e. relational, complexity, learning) processes to take purposeful action in spite of 'unknowable' complexity. From my experience, I would add a third observer here, called the 'linear development project manager'. This observer spies project goals and objectives, and preselected best practice tools and activities that he or she can apply towards them, in any development situation. This worldview neither recognises systems 'out there' that can be engineered - which is at least systemic in the hard tradition - nor complexity and confusion, which can be approached purposefully through learning-approaches (Checkland 1993). Instead, this observer's spyglass is a project lens, through which he or she sees well-identified problems and widely acceptable project ends. The worldviews that have informed this project are limited to donors and project designers within the organisation itself, who assume that enough resources, a solid plan (Reeler 2007: 6) and efficient project execution can result in delimited, predetermined change. Within this worldview if I am the observer (and I have been), I only need to strengthen my internal processes, systems, management and leadership in order to operate productively and efficiently. And I only pursue relationships, or engage with the worldviews of primary stakeholders, to the extent that they instrumentally help me achieve my goals.

When I refer to purposefulness within complexity, I share the worldview of observer two and adopt soft systems thinking. The core 'worry' mentioned earlier is that development practitioners will take complexity to just be another challenge that now needs to be mastered, and will look to try to engineer even better 'solutions' than before, missing the fundamental message that '...no one is in overall control of what is happening, and although patterns of relating tend in a particular direction, the exact global pattern that emerges is unpredictable' - 'no matter how clear and 
logical the strategy pursued by any actor' (Mowles et al. 2008: 810, 815).

With purposeful capacity development, within complexity, the idea is to ask what the situation calls for and then purposefully try to act in a way that supports emergent change in the most thoughtful and intentional way possible. I agree with the Land et al.'s (2009: 2) assertion that capacity development 'cannot be managed in a conventional sense...', but that much about capacity development, 'can be understood and influenced'. But I believe that that influence should be purposeful - purposefulness being understood as the emergent property of thoughtfully and intentionally linked activities in any human activity system (Checkland 2000: S14) - that continually takes complexity into account before, during and after acting. This will favour iterative, emergent approaches to capacity development that are less concerned with 'clos[ing] the gap between planned and executed activities; rather, approaches which are focused on reducing the gap between 'the plan' and realities on the ground, including emerging opportunities and challenges' (Ortiz and Taylor 2009: 28).

But this requires a shift in worldview, a changing of cultural assumptions about how the world works and what we should do about it. A shift to non-linear, yet purposeful capacity building requires critical reflection on why we think and operate in linear ways in the first place, as well as reflection on other assumptions we hold about change. Otherwise we may fall back into our predisposed ways of thinking about and approaching change.

\section{The importance of surfacing worldviews and theories of change for purposeful capacity development}

'Development practice is informed by theories of change, but individuals and organisations may not make them explicit. Practitioners may be unaware of the extent to which strategic choices and debates are informed by disparate thinking about how history happens and the role of purposeful intervention for progressive social change.' (Eyben et al. 2008: 201)

Building on this assumption, if it is true that development practitioners are guided by theories of change, perhaps we ought to surface those assumptions to have a deeper debate on the ways they inform and affect the way we approach our capacity development work? Key stakeholders often have deeply felt but divergent views about what organisational priorities ought to be (Bradach, Tierney and Stone 2008: 91), and making those views and corresponding theories of change explicit between colleagues can reveal that much of our disagreement may be due to different but possibly buried ways of understanding how change happens, leading to favouring one explanation over another when we debate strategic choices (Eyben et al. 2008: 201).

Theories of change exist at every level of society, including families, communities, networks and other social groups, but also at the level of institutional (i.e. cultural and societal) norms and values (Scott 2007), where they create hard and soft boundaries of permissible behaviour and ways of thinking about and acting on change, even as they themselves are continually shaped by individuals and organisations and their theories and practices of change. Eyben et al. note that ' $[\mathrm{e}] \mathrm{ven}$ when we do not realise it, we are using theories every day in explaining social reality to ourselves and to others. These theories include explanations of social change absorbed through our education and upbringing; they may have become so embedded that we no longer question whether they are the most useful for our purpose, or if we are using them as well as we could' (Eyben et al. 2008: 201). Theories of change within the field of development studies are far from unique and are derived from approaches to change that have emerged in history, politics, sociology, and other areas of academic inquiry (Krznaric 2007: 45).

At the individual level, one's theories of change might represent multiple visible, invisible, implicit, explicit, positive and/or negative beliefs, life experiences, assumptions, and elements of culture and power that have shaped and continue to shape us. According to Guijt, theories of change are 'the overarching assumptions and philosophies that influence individual visions and understandings. They shape how each person thinks change occurs in society' (Guijt 2007: 30, citing VeneKlasen in 2006).

Theories of change are intrinsically linked to values, passions, and beliefs: 
The theory of change that guides personal choices is philosophical, historical, political, psychological and experiential, i.e. ideological. It includes personal standpoints or worldviews based on class, ethnicity, belief systems, personal values, commitment, etc. It also includes the short and long term agenda and interest of those involved... in the process of social change. (Guijt 2007: 29)

We as individuals carry these theories of change with us everywhere we go, including to the workplace, as well as to broader interactions with our families and societies, where we use them as lenses to interpret and make sense of the world, or as maps to help us navigate our roles and actions in the world. They are our cultural assumptions, our conscious and 'unconscious, taken-for-granted beliefs, perceptions, thoughts and feelings, [which are our] ultimate source of values and action' (Schein 2004: 26).

Bourdieu's (1998: 7) theory of 'habitus' is useful when thinking about theories of change. Habitus are people's predispositions or tastes which emerge from the ongoing 'struggle for social distinction' (Swartz 1997: 6) within a given field of action. According to Bourdieu 'habitus are generative principles of distinct and distinctive practices - what the worker eats, and especially the way he eats it, the sport he practices and the way he practices it, his political opinions and the way he expresses them are systematically different from the industrial owners corresponding activities... They make distinctions between what is good and what is bad, between what is right and what is wrong, between what is distinguished and what is vulgar, and so forth' (Bourdieu 1998: 8).

Habitus are socially acquired, they 'can... be transferred across different domains, producing consistency in consumption patterns (such as in music or food) and in other lifestyle choices, such as in political or cultural preferences within and among different social classes. Thus, we construct our social world by applying socially derived categories of judgment, which we share with others who were exposed to the same conditions and experiences' (Moncrieffe 2006: 36). Therefore, habitus can be regarding as the socially acquired predispositions that help construct our theories of change.
At the organisation level, theories of change might represent a social change organisation's implicit and explicit 'collective' understandings of how development (change) 'happens' with regards to the issues that it exists to address (mission/ purpose). This might include a particular understanding of the demands/needs of primary stakeholders $^{7}$ and the conditions that are needed to contribute to meaningful change, given the complexities (e.g. current conditions, other actors, power, culture, systems, etc.) in the broader environment, and within the organisation itself (Morgan, G. 2006: 39). Organisational theories of change are culturally embedded, from visible organisational structures and processes, to espoused beliefs and values expressed in organisational strategies, goals and philosophies, to the more unconscious underlying assumptions on change (paraphrased from Schein 2004: 26). These cultural dispositions are present in a group's unconscious and have powerful influences on a group's behaviour (Schein 2004: 15). Again, if we relate these cultural dispositions to 'habitus', their generative nature (i.e. they lead to action) is highlighted, which serves to reinforce and thus reproduce deeply held assumptions (Swartz 1997: 101).

As people in organisations assign and continually re-create levels of group identity (including elements of mission and vision, programmes, projects and activities, etc.) in relation to each other, and to their multiple interactions with people and factors outside the organisation, organisational theories of change are continually being reshaped. The organisational cultures and processes that continually emerge in the process can outlast or transcend particular personalities that transition through the organisation (Schein 2004: 14). But they are never pure or static (Schein 2004: 8), and, at any given moment, organisational identity always contains elements of the worldviews and theories of change of the individuals within it.

An important implication of the systemic nature of theories of change for capacity development is that assumptions at the organisational level need to be analysed in the light of broader societal as well as individual assumptions about change. Theories of change exist both inside and outside of individuals - individuals and society are constructed relationally as if they are two dimensions of the same social reality (Swartz 
According to Bourdieu, habitus are generated via a power struggle over different types of symbolic capital, e.g. economic, cultural or social capital - which are used by actors in different relative positions within a given field (Bourdieu 1998: 5). As Navarro notes, '[i]ndividuals mobilise resources in order to assure their position in the social order and these resources are forms of capital when they function as a social relation of power' (Navarro 2006: 17). Economic and cultural are the most important of the different types of symbolic capital (Bourdieu 1998: 6), but their relative value differs depending on the particular field in which they operate (Bourdieu and Wacquant 1992: 98).

Symbolic capital 'does not exist and function except in relation to a field' (Bourdieu and Wacquant 1992: 101). As such, if capacities were to be considered a form of symbolic capital, it would be important to understand the boundaries and value system of the field of play. Via continual reflective practice, I believe that we can better understand the concept of capacity as a form of symbolic capital, its value conditioned by the cultural habitus that emerges as the individuals within an organisation, and the organisation within broader fields of play, struggle for legitimacy, survival and social distinction. This can help clarify whether capacities are being sought and developed in order to contribute to preserving or transforming 'the configuration of forces' within existing power structures which otherwise tend to reproduce themselves (Bourdieu and Wacquant 1992: 101, 103).

1997: 96). Assumptions are 'true' to those who make them, and ' $[\mathrm{o}]$ nce people make sense of their world collectively, creating norms and developing tacit assumptions, those norms and assumptions define reality, the individual's identity and group membership' (Schein 2006: 297). When made explicit, these assumptions can reveal a lot about the motivations behind our ways of seeing and acting in the world including linear worldviews that are inimical to complex social change. And as Moncrieffe notes, when these and other assumptions are left unrevealed or un-discussed, they can perpetuate unhealthy power relationships:

As development actors, we tend to downplay our own biases - assuming we do recognise them and to assert our objectivity. Yet, our own socially acquired dispositions, including our prejudices, infiltrate our practice and are consequential for outcomes. Development actors, through their actions and inaction, can have a role in upholding the adverse power relationships that sustain inequalities and injustices (Moncrieffe 2006: 35).

\section{Conclusion}

Development - 'moves in directions where its trajectory and momentum are taking it, and where multiple actors and influences - e.g. policies, internal and external power structures, culture, weather, etc. - and other visible and invisible factors push and pull it' (Ortiz and Taylor 2009: 27). Social change conditions are emergent, i.e. they have properties which are more than the sum of their parts (Flood 2001: 133), and which are the result of multiple factors that complexity renders 'inherently unknowable to the human mind' (Flood 2001: 86). Capacity development - 'that emergent combination of individual competencies, collective capabilities, assets and relationships that enables a human system to create value' (Baser and Morgan 2008: 3) - is itself non-linear and emergent. So, just as development interventions cannot be thought of to linearly 'cause' development outcomes, capacity strengthening cannot be thought of to linearly 'cause' improved capacities, nor can these capacities be assumed to contribute linearly to social change.

Capacity strengthening approaches are needed that help social change organisations better understand the emergent conditions needed for change, and ask questions that allow them to better align their programmatic offerings and internal processes, systems and capacities with the social change they aim to support - in purposeful, yet non-linear ways. Even if individuals and organisations do not make them explicit, development practice is informed by theories of change (Eyben et al. 2008: 201). Taylor 
and Clarke (2008: 16) note that 'different actors engaged in capacity development processes tend not to articulate their own theoretical understandings of how change happens'. Yet if organisational theories of change and their underlying worldviews are not surfaced and debated, existing linear intervention models that pretend the world is simple and controllable may continue to dominate the scene, with capacity building simply being designed uncritically to help organisations carry out that worldview more efficiently (e.g. with better leadership and bestpractice management systems).

Checkland and Poulter (2006: 172) note that 'any process for intervening sensibly in real-world situations to bring about "improvement" must have some ideas - some theory - about the nature of social reality, whether it is made explicit or not... which makes any chosen process of intervention "sensible". Reeler (2007: 2) adds

\section{Notes}

1 The first two paragraphs of this section are paraphrased from Ortiz and Taylor (2009).

2 These capabilities, in addition to the capability 'to carry out technical, service delivery and logistical tasks,' form the (ECDPM) capabilities model. Also see the insightful table on adaptive capacities in Horton et al. (2003: 28-9).

3 See www.merriam-webster.com/dictionary/ capacity

4 For a discussion on the problems associated with a focus on capacity for immediate performance, and the need to also think of capacity in terms of reserve or 'standing capacity', see Ortiz and Taylor (2009: 21-4). This document can be accessed at: www.iiep.unesco.org/en/capacity-development/ capacity-development-strategies/range-ofstudies/learning-purposefully.html

5 For example, the rise and continued rise of non-governmental organisations (NGOs) is chronicled in multiple sources (Edwards and Fowler 2002; Fowler 1997; Bebbington, Hickey and Mitlin 2008; Lewis 2007), as are warnings of the perils of NGO complacency if they fail that ' $[w]$ e need good theories of social change for building the thinking of all involved in processes of development, as individuals, as communities, organisations, social movements and donors'. Capacity development processes should help make these theories of change explicit because unless an organisation has clarity on what it is trying to accomplish, taking into account the complexities of the situation it is trying to affect, it is difficult to know what would make any particular capacity development meaningful. Capacity strengthening interventions have a better chance of purposefully contributing to change if they are in concert with ongoing, emergent development processes, in a way that is meaningful to key stakeholders, and to the extent that they take the inherent complexities of development and capacity into account (Ortiz and Taylor 2009). A systemic surfacing of theories of change is one way of moving in the direction of more purposeful capacity development.

to better define their roles and present alternatives to mainstream development practices (Mitlin, Hickey and Bebbington 2007; Edwards 2008; Bebbington et al. 2008; Edwards and Fowler 2002), improve their overall organisational effectiveness (Baser and Morgan 2008; Edwards and Fowler 2002; Fowler 1997; Kaplan 1999; Lewis 2007; Morgan, P 2006), downward accountability (Edwards and Hulme 2002; Jordan and Tuijl 2006; Kaplan 1999; Kilby 2006), utilise more appropriate management practices (Edwards and Fowler 200; Moore 2000; Mowles et al. 2008; Lewis 2007; Dar and Cooke 2008), and develop real constituencies and local relevance (Kaplan 1999; Kilby 2006; Bano 2008).

6 Checkland has not expressed this as a warning for capacity development. Rather, I use his explanation of how a 'hard systems stance' is problematic in 'soft' situations to highlight how maintaining the fine balance between complexity and purposefulness can be problematic.

7 Or demands arising from major thematic issues, when primary stakeholders are not the main justification for action. 


\section{References}

Bakewell, O. and Garbutt, A. (2005) The Use and Abuse of the Logical Framework Approach, Stockholm: Swedish International Development Cooperation Agency (Sida)

Bano, M. (2008) 'Dangerous Correlations: Aid's Impact on NGOs' Performance and Ability to Mobilize Members in Pakistan', World Development 36: 2297-313

Baser, H. and Morgan, P. (2008) Capacity, Change and Performance: Study Report, Maastricht: European Centre for Development Policy Management (ECDPM)

Bebbington, A.; Hickey, S. and Mitlin, D. (eds) (2008) Can NGOs Make a Difference: The Challenge of Development Alternatives, London: Zed Books

Bourdieu, P. (1998) Practical Reason, Stanford: Stanford University Press

Bourdieu, P. and Wacquant, L. (1992) An Invitation to Reflexive Sociology, Chicago: University of Chicago Press

Bradach, J.L.; Tierney, T.J. and Stone, N. (2008) 'Delivering on the Promise of Nonprofits', Harvard Business Review 86.12: 88-97

Britton, B. (2005) Organizational Learning in NGOs: Creating the Motive, Means and Opportunity, Oxford: International NGO Training and Research Centre (INTRAG)

Burns, D. ( 2007) Systemic Action Research: A Strategy for Whole System Change, Bristol: Policy Press

Checkland, P. (2000) 'Soft Systems Methodology: A Thirty Year Retrospective', Systems Research and Behavioral Science 17.S1: S11-S58

Checkland, P. (1993) Systems Thinking, Systems Practice, Chichester: Wiley

Checkland, P. and Poulter, J. (2006) Learning for Action: A Short Definitive Account of Soft Systems Methodology and its use for Practitioners, Teachers and Students, Chichester: Wiley

Dar, S. and Cooke, B. (eds) (2008) The New Development Management, London: Zed Books

Earl, S.; Carden, F. and Smutylo, T. (2001) Outcome Mapping: Building Learning and Reflection into Development Programs, Ottawa: International Development Research Centre (IDRC)

Earle, L. (2002) Lost in the Matrix: The Logframe and the Local Picture, Oxford: International NGO Training and Research Centre (INTRAC)

Edwards, M. (2008) 'Have NGOs Made a Difference? From Manchester to Birmingham with an Elephant in the Room', in
A. Bebbington, S. Hickey and D. Mitlin (eds) Can NGOs Make a Difference: The Challenge of Development Alternatives, London: Zed Books: 38-52

Edwards, M. and Fowler, A. (eds) (2002) The Earthscan Reader on NGO Management, London: Earthscan

Edwards, M. and Hulme, D. (2002) 'NGO Performance and Accountability: Introduction and Overview', in M. Edwards and A. Fowler (eds), The Earthscan Reader on NGO Management, London: Earthscan: 187-203

Eyben, R.; Kidder, T.; Rowlands, J. and Bronstein, A. (2008) 'Thinking About Change for Development Practice: A Case Study for Oxfam GB', Development in Practice 18.2: 201-12

Flood, R.L. (2001) 'The Relationship of "Systems Thinking” to Action Research', in P. Reason and H. Bradbury (eds) Handbook of Action Research: Participative Inquiry and Practice, $1 \mathrm{st}$ edn, London: Sage: 133-44

Flood, R.L. (1999) Rethinking the Fifth Discipline: Learning Within the Unknowable, London: Routledge

Fowler, A. (1997) Striking a Balance: A Guide to Enhancing the Effectiveness of Non-governmental Organizations in International Development, London: Earthscan

Guijt, I. (2007) Assessing and Learning for Social Change, Brighton: IDS

Hailey, J.; James, R. and Wrigley, R. (2005) Rising to the Challenges: Assessing the Impacts of Organizational Capacity Building, Oxford: International NGO Training and Research Centre (INTRAC)

Hayward, C.R. (1998) 'De-Facing Power', Polity 31.1: 1-22

Horton, D.; Alexaki, A.; Bennett-Lartey, S.; Brice, K.N.; Campilan, D.; Carden, F.; de Souza Silva, J.; Duong, L.T.; Khadar, I.; Maestrey Boza, A.; Kayes Muniruzzaman, I.; Perez, J.; Somarriba Chang, M.; Vernooy, R. and Watts, J. (2003) Evaluating Capacity Development: Experiences from Research and Development Organizations Around the World, The Hague: International Service for National Agricultural Research (ISNAR) (also Technical Centre for Agricultural and Rural Cooperation (CTA) and International Development Research Centre (IDRG))

James, R. and Wrigley, R. (2007) Investigating the Mystery of Capacity Building: Learning from the Praxis Programme, Oxford: International NGO Training and Research Centre (INTRAC) 
Jordan, L. and Tuijl, P.V. (eds) (2006) NGO Accountability: Politics, Principles and Innovations, London: Earthscan

Kaplan, A. ( 1999) The Developing of Capacity, Cape Town: Community Development Resource Association (CDRA)

Kilby, P. (2006) 'Accountability for Empowerment: Dilemmas Facing Non-Governmental Organizations', World Development 34.6: 951-63

Krznaric, R. (2007) How Change Happens: Interdisciplinary Perspectives for Human Development, Oxford: Oxfam

Lafond, A. and Brown, L. (2003) A Guide to Monitoring and Evaluation of Capacity-Building Interventions in the Health Sector in Developing Countries. MEASURE Evaluation Manual Series, Chapel Hill: Carolina Population Center, University of North Carolina

Land, T.; Hauck, V. and Baser, H. (2009) Capacity Development: Between Planned Interventions and Emergent Processes. Implications for Development Cooperation, Maastricht: European Centre for Development Policy Management (ECDPM)

Lewis, D. (2007) The Management of NonGovernmental Development Organizations, London: Routledge

Lopes, C. and Theisohn, T. (2003) Ownership, Leadership and Transformation: Can we do Better for Capacity Development?, London: Earthscan

Lusthaus, C.; Adrien, M-H. and Perstinger, M. (1999) Capacity Development: Definitions, Issues and Implications for Planning, Monitoring and Evaluation, Universalia Occasional Paper, www.universalia.com/files/occas35.pdf (accessed 1 February 2010)

Mitlin, D.; Hickey, S. and Bebbington, A. (2007) 'Reclaiming Development? NGOs and the Challenge of Alternatives', World Development 35.10: 1699-720

Moncrieffe, J. (2006) 'The Power of Stigma: Encounters with "Street Children" and "Restavecs", IDS Bulletin 37.6: 34-46

Moore, M.H. (2000) 'Managing for Value: Organizational Strategy in For-Profit, Nonprofit, and Governmental Organizations', Nonprofit and Voluntary Sector Quarterly, 29(suppl.1): 183-208

Morgan, G. (2006) Images of Organization, London: Sage

Morgan, P. (2006) The Concept of Capacity, Maastricht: European Centre for Development Policy Management (ECDPM), www.ecdpm.org/Web_ECDPM/Web/Content/
Download.nsf/0/EF596EFCBB8A417DG12571 78004AEB5B/\$FILE/Morgan\%20-\%20Capacity \%20-\%20What\%20is\%20it\%2010052006.pdf (accessed 1 February 2010)

Morgan, P. (1997) The Design and Use of Capacity Development Indicators, Gatineau: Canadian International Development Agency (CIDA)

Mowles, C.; Stacey, R. and Griffin, D. (2008) 'What Contribution can Insights from the Complexity Sciences Make to the Theory and Practice of Development Management?', Journal of International Development 20.6: 804-20

Navarro, Z. (2006) 'In Search of a Cultural Interpretation of Power: The Contribution of Pierre Bourdieu', IDS Bulletin 37.6: 11-22

OEGD (2006) The Challenge of Capacity Development Working Towards Good Practice, Paris:

Organisation for Economic Cooperation and Development

Ortiz Aragón, A. and Taylor, P. (2009) 'Learning Purposefully in Capacity Development: Why, What and When to Measure?', in International Institute for Educational Planning (ed.), Rethinking Capacity Development, Paris: International Institute for Educational Planning (IIEP)

Ramalingam, B. and Jones, H. (2008) Exploring the Science of Complexity: Ideas and Implications for Development and Humanitarian Efforts, London: Overseas Development Institute

Reeler, D. (2007) A Theory of Social Change and Implications for Practice, Planning, Monitoring and Evaluation, Cape Town: Community Development Resource Association (CDRA) Schein, E.H. (2006) 'From Brainwashing to Organizational Therapy: A Conceptual and Empirical Journey in Search of "Systemic" Health and a General Model of Change Dynamics. A Drama in Five Acts', Organization Studies 27.2: 287-301

Schein, E.H. (2004) Organizational Culture and Leadership, San Francisco: Wiley

Scott, W.R. (2007) Institutions and Organizations: Ideas and Interests, London: Sage

Swartz, D. (1997) Culture and Power: The Sociology of Pierre Bourdieu, London: University of Chicago Press

Taylor, P. and Clarke, P. (2008) Capacity for a Change, Brighton, IDS

Watson, D. (2006) Monitoring and Evaluation of Capacity and Capacity Development, Maastricht: European Centre for Development Policy Management (ECDPM) 